\title{
A Visão Convencional Sobre a Abertura Financeira e suas Mutações Recentes
}

\author{
- André Martins Biancareli*
}

\begin{abstract}
Resumo
O presente trabalho tem por objetivo proceder a uma revisão crítica da literatura convencional sobre a abertura financeira, com foco nos países em desenvolvimento. Desde os benefícios teóricos clássicos advindos da integração financeira, até as abordagens mais recentes que se propõem a repensar a globalização, o esforço é de caracterização e análise da evolução da visão convencional. Neste caminho, são apreciados também os debates empíricos relativos ao tema, os posicionamentos dissidentes no interior do mainstream economics, e os novos elementos apontados pelo chamado balance sheet approach (como a "intolerância ao endividamento", o "descasamento de moedas" e o "pecado original"). Os resultados desta evolução, apesar dos inegáveis progressos em relação aos argumentos que orientaram os processos de abertura nos países em desenvolvimento nas décadas de 1980 e 1990, compõem um quadro de avanços pontuais e isolados, que não permitem identificar uma verdadeira revisão teórica.
\end{abstract}

\section{Palavras-Chave}

abertura financeira, países em desenvolvimento, visão convencional

\begin{abstract}
This paper aims at building a critical revision of the conventional literature on the subject of financial opening, focusing on developing countries. Departing from classical theoretical benefits to more recent approaches which try to rethink globalization, the effort is to describe and analyze the evolution inside the conventional wisdom. The empirical debate on these issues; the dissidents inside the maistream and the new elements present in the "balance sheet approach" llike "debt intolerance", "currency mismatch" and "orginal sin") are also examined. The results of this evolution, despite the distance from the original arguments that have guided the opening process in developing countries in the 1980's and 1990's, compose a picture of partials and isolated changes, which are not enough to identify a real theoretical revision.
\end{abstract}

\section{Keywords}

financial opening, developing countries, conventional wisdom

\section{JEL Classification}

B00, F32, F36

\footnotetext{
* Instituto de Economia da Universidade de Campinas (IE-Unicamp) e Centro de Estudos de Conjuntura e Política Econômica (Cecon - IE-Unicamp). E-mail: andremb@eco.unicamp.br.

Endereço para contato: Universidade Estadual de Campinas - Instituto de Economia. Caixa Postal 6135. Campinas - SP. CEP: 13.083-857.

(Recebido em julho de 2009. Aceito para publicação em setembro de 2010).
} 


\section{Introdução}

Nos últimos tempos, principalmente após as crises cambiais e financeiras que se espalharam pelos chamados "mercados emergentes" no final dos anos de 1990, um tema marcou presença constante nas discussões políticas e acadêmicas sobre a economia internacional: a liberalização ou integração financeira destas economias à "globalização", em seus efeitos positivos e negativos. O termo "abertura financeira" - entendida como a eliminação de restrições à livre movimentação dos fluxos financeiros entre as fronteiras nacionais - parece o mais adequado para designar estas mudanças que, com intensidade variável, foram implementadas pela maioria dos países em desenvolvimento, a partir do final dos anos de 1980.

Este processo - aqui julgado fundamental para entender as possibilidades e dificuldades com as quais se deparou esta parte do mundo nas últimas décadas - é tema de uma volumosa e complexa produção de argumentos econômicos que o sustentam teoricamente. Porém, seria ingênuo supor que mudanças de tal envergadura estejam isentas de pressões, mais ou menos explícitas, por parte dos agentes interessados. Mesmo que as medidas de política nem sempre guardem relação direta com o debate teórico, parece bastante relevante observá-lo com atenção. A evolução das discussões, nos últimos anos, só amplia tal relevância.

Entende-se que, desde os argumentos clássicos a favor da abertura até os mais recentes, passando por uma série de dificuldades (de diferentes naturezas) enfrentadas pelas formulações tradicionais, é possível caracterizar uma evolução da visão convencional, que traz várias novidades em relação às ideias originais que orientaram os processos de abertura nos países em desenvolvimento no período de globalização financeira.

Mas não se pretende, é prudente esclarecer de início, resumir ou organizar de forma neutra a produção acadêmica sobre o tema - tarefa de resto impossível em se tratando de ciências humanas. Parte-se aqui de um posicionamento assumidamente crítico em relação a essa frente de reformas liberalizantes - seja pelo modo como foram levados a cabo os processos nacionais de abertura, seja por suas implicações negativas sobre os países em desenvolvimento. O objetivo é, antes de tudo, avaliar em que medida os desenvolvimentos recentes configuram ou não uma revisão teórica relevante, e as implicações disto para a melhor compreensão do debate acadêmico contemporâneo.

Neste trabalho, visão convencional (ou mainstream economics) é entendida, seguindo a definição de Colander et al. (2004), como aquela que a "elite da profissão" considera aceitável. Por este último termo entre aspas, os autores referem-se aos 
principais economistas, vinculados aos mais destacados centros de produção acadêmica internacional na área. Assim, são objeto de exame as contribuições de autores distintos, que conservam entre si o reconhecimento dos pares mais importantes e que, em geral, comungam da opção pela modelagem dos fenômenos econômicos. Esta agregação comporta, portanto, variedade nas interpretações e conclusões, e não se restringe ao que se chama de ortodoxia. ${ }^{1}$

Foi dada prioridade à literatura internacional - não por desconhecimento ou demérito da produção brasileira sobre o tema, mas pelo entendimento de que, neste aspecto específico, tal produção não se enquadra na visão convencional tal como definida acima. Destaque-se também, de partida, que não é objeto do texto a vasta e importante literatura crítica aos processos de abertura nos países em desenvolvimento - campo em que, certamente, a literatura nacional avançou mais. ${ }^{2}$

Além desta introdução, o artigo está dividido em mais duas grandes seções. Na primeira, a visão convencional começa a ser exposta por meio dos quatro benefícios clássicos advindos da abertura. Na segunda, são apresentados e analisados, em sequência, cinco frentes de desafios e revisões enfrentados pelo mainstream economics. Breves conclusões encerram o trabalho.

\section{A Globalização e os seus Benefícios}

A defesa da abertura financeira costuma partir, nas análises convencionais, de alguns conhecidos argumentos. Exemplos podem ser encontrados em Fischer (1998) e em Obstfeld e Taylor (2004, seção 1.1), que apontam quatro benefícios teóricos: (i) compartilhamento e diversificação internacional de riscos; (ii) financiamento de desequilíbrios passageiros de balanço de pagamentos; (iii) acesso à poupança externa para o financiamento do investimento e do desenvolvimento, ${ }^{3}$ e (iv) disciplina sobre a política econômica.

1 Para uma crítica deste conceito e proposição de definições alternativas para economia neoclássica, mainstream, ortodoxia e heterodoxia, ver Dequech (2007-2008).

2 Neste sentido, podem ser citados como bons exemplos nacionais o artigo de Carvalho e Sicsú (2004) sobre controles de capital, bem como todos os capítulos reunidos em Sicsú e Ferrari Filho (2006). Damasceno (2007) também procede a uma revisão crítica da literatura convencional (ainda que mais focalizada do que a aqui pretendida) e resume os argumentos de uma crítica de inspiração pós-keynesiana.

3 Esses dois últimos itens são unidos em torno de um mesmo título ("comércio intertemporal") que tem claramente duas dimensões, uma de curto prazo, referente ao ajuste no balanço de pagamentos ("... an international capital market allows countries to smooth out over time the dynamic effects of predictable income fluctuations. A country whose output is temporarily low, for example, can borrow to support consumption, repaying the loans later after the anticipated output increases", p. 8) e outra, relativa ao longo prazo e ao financiamento do investimento ("A country that has rich opportunities, but that generates little savings of its own, can tap the international market to exploit its investment potential without massive short-run consumption cutbacks", p. 9). 
Outros exemplos na literatura poderiam ser citados, com poucas variações. Kose et al. (2006, seção II) dividem os benefícios em três grupos: "crescimento" (com efeitos diretos na forma da atração de poupança externa e dos efeitos de spill-over por alguns tipos de fluxo, e indiretos na forma da especialização produtiva permitida pelo compartilhamento de riscos, da disciplina macro e do desenvolvimento financeiro doméstico); "volatilidade" (seria possível compartilhar os riscos decorrentes da especialização produtiva), e, finalmente, "co-movimento" entre as diferentes economias.

Tratando da abertura dos mercados de ações, Bekaert e Harvey (2003) apresentam modelo teórico na mesma direção: quando se transita de um mercado segmentado para um integrado, o resultado seria a entrada maciça de investidores estrangeiros, levando ao aumento permanente dos preços das ações e, com isso, a uma queda nos retornos esperados nesse tipo de aplicação - o que também significa uma redução no custo do capital obtido por esta via. Assim, as emissões primárias seriam incentivadas e o investimento, beneficiado, ampliando a taxa de crescimento econômico. Tudo isso, de certa forma, está resumido na lista de quatro argumentos de Obstfeld e Taylor (2004).

Em relação ao item (iv), a ideia de supervisão ou disciplina pressupõe a existência de práticas de política econômica corretas e unanimemente reconhecidas como tal. Apenas interesses políticos e/ou a falta de preparo dos policy makers explicariam o desvio desse rumo. A outra face do argumento também se baseia na hipótese da eficiência dos mercados: a certeza na capacidade de monitoramento e correção por parte dos fluxos de capital desregulados, portadores desse conhecimento e que puniriam os eventuais erros.

Quanto aos demais, a previsão de uma diversificação internacional de carteiras ponto (i) - obedece à lição de "não colocar todos os ovos em uma mesma cesta": distribuindo os recursos em ativos, cujo valor esteja atrelado a fatores não correlacionados, o risco esperado seria reduzido. E, do ponto de vista dos recebedores desses fluxos, a possibilidade de negociação dos seus riscos com os de outras economias, desde que não relacionados entre si, também permitiria redução dos estragos em situações adversas, além de incentivar empreendimentos mais rentáveis e com novas tecnologias - cujos riscos, também maiores, inibem o investidor isolado. ${ }^{4}$ Configurase assim um ganho de bem-estar de natureza global, e justificam-se os benefícios

4 Numa das principais referências sobre os ganhos da diversificação de riscos no plano internacional (OBSTFELD, 1994), é lembrada a frase de Arrow (1971, p. 137) que esclarece esse ponto: "...the mere trading of risks, taken as given, is only part of the story and in many respects the less interesting part. The possibility of shifting risks, of insurance in the broadest sense, permits individuals to engage in risky activities that they would not otherwise undertake". 
previstos na forma de redução da volatilidade e aumento do co-movimento do consumo e do produto.

Já as questões do financiamento (iii) e da poupança externa (iv) têm implicações mais complexas, mas igualmente apontam para um ganho em ambos os lados das transações financeiras internacionais. Do ponto de vista dos ofertantes, o raciocínio é decorrência dos modelos neoclássicos das trocas internacionais, na linha HecksherOhlin: o capital abundante, nos países desenvolvidos, desde que desimpedido, tende a se deslocar às melhores oportunidades de investimento e às mais elevadas taxas de remuneração das economias com escassez de recursos para a inversão. Para estas, a importação de poupança seria o caminho para a superação do que é uma de suas deficiências estruturais e, com tal absorção, se ampliariam não apenas as taxas de investimento como também as perspectivas de crescimento e desenvolvimento. Mais do que isso, um efeito indireto da redução da escassez de capital seria a queda no seu custo (rumo à equalização internacional das taxas de remuneração), também contribuindo para a elevação do investimento.

Trata-se de ponto fundamental: um dos resultados principais da aplicação da macroeconomia convencional à análise dos problemas dos países em desenvolvimento - a identificação da carência de recursos previamente poupados como limitante para o montante do investimento - é resolvido aqui com o apelo à contribuição da poupança externa, possibilitada pela eliminação dos entraves à livre movimentação do capital por entre as fronteiras, e que não só coloca à disposição maior quantidade de recursos, como também reduz as taxas de juros e outras taxas de rendimento. Talvez esse tenha sido o mais poderoso dos argumentos endereçados ao longo dos anos de 1990 aos países em desenvolvimento.

Ainda nesse nível de generalidade, a ideia da absorção de poupança externa se desdobra em um raciocínio contábil simples: se a poupança doméstica é insuficiente para financiar o investimento, pode-se incorrer em déficit em conta corrente para suplementar esse montante. Seria um exemplo de comércio intertemporal, com o país que absorve a poupança externa importando consumo presente e exportando futuro (na forma do pagamento dos empréstimos), e o país "fornecedor" fazendo a troca intertemporal no sentido contrário.

Na literatura sobre o tema, tal ideia também assumiu a forma da postulação da existência de um hiato de recursos (simbolizado pelo déficit em conta corrente), a ser coberto pela poupança ou pelo financiamento externo, com ganhos em termos de bem-estar e equilíbrio intertemporal do balanço de pagamentos para ambos os lados. ${ }^{5}$ O raciocínio também sugere que, na presença de ampla liberdade de entrada

5 Ver, por exemplo, Obstfeld e Rogoff (1996, cap. 1). 
e saída dos fluxos de capital, países em desenvolvimento apresentem déficits, com o capital externo financiando o balanço de pagamentos e o investimento interno. Mais do que isso, para o conjunto da economia mundial integrada financeiramente, a previsão seria de uma crescente desvinculação entre as taxas internas de poupança e as de inversão. ${ }^{6}$

Levado às últimas consequências, esse raciocínio explica os intensos debates suscitados pelos resultados obtidos por Feldstein e Horioka (1980). De maneira surpreendente, haveria uma alta e estável correlação entre poupança e investimento domésticos no período 1960-1974 para uma amostra de 16 países da OCDE. Concluiu-se então que, ao contrário do imaginado, a mobilidade do capital não era alta nem entre aquelas economias, e que, também contrariando o senso comum, tal mobilidade não havia se elevado com a desorganização da ordem de Bretton Woods. Muita tinta foi gasta para tentar solucionar tal puzzle - que parece, antes de qualquer coisa, decorrente dos pressupostos macroeconômicos discutíveis sobre os quais o raciocínio é construído.

Independente dos detalhes desta discussão específica, o episódio é ilustrativo de dois fenômenos que se acentuariam no período mais recente: os desafios sofridos por todo esse rol de argumentos favoráveis à mobilidade internacional de capitais, e a dificuldade, no esforço de resposta a esses questionamentos, de rever as bases teóricas mais fundamentais sobre as quais eles estão assentados. É destes processos que se trata a partir de agora.

\section{Desafios e Reações no Interior da Visão Convencional}

Cunha (2001) denomina "reação teórica" o movimento de reavaliações no mainstream acadêmico-financeiro internacional a partir da crise asiática. Com o benefício do tempo transcorrido, pode-se dizer que essa reação se desdobrou em várias direções distintas - que têm, nas crises ali iniciadas, um elemento catalisador importante, mas que, na realidade, vêm de antes e vão muito além dos aspectos diretamente relacionados a elas. Destas direções, cinco interessam mais de perto aqui.

\subsection{Um Negócio entre os Ricos: Os Capitais Não Fluem para os Países Pobres}

A primeira frente de batalha é a do debate quantitativo, no qual duas temáticas se destacam. Uma delas se refere à mensuração da integração financeira internacional

6 Para duas diferentes abordagens críticas desse argumento, ver Resende (2006) e Bresser-Pereira e Gala (2007), entre outros. 
e à participação dos países em desenvolvimento nela. O capítulo 7 de Obstfeld e Taylor (2004) tem título que resume as conclusões sobre o ponto: Uneven integration. Quantificando a integração de diferentes maneiras, e dividindo o mundo entre ricos (membros da OCDE) e pobres, emerge uma série de resultados inesperados.

Para os ricos, os dados dos estoques de ativos e passivos externos sobre PIB das últimas décadas mostram uma explosão no movimento bruto, nas duas direções. Mas, contrariamente à previsão teórica de seu papel exportador de capitais para os pobres, o resultado líquido permanece muito próximo de zero. Essa impressão de "jogo entre os ricos" se acentua quando são observados os dados de fluxos: a conta corrente como parcela do PIB dos países em desenvolvimento só é significativamente deficitária em alguns períodos isolados (a segunda metade dos anos de 1970 e parte da década de 1990, até 1997) e, após a crise asiática, verificam-se crescentes superávits (i.e., exportação de capital). Um resultado muito mais próximo do equilíbrio - com forte deterioração e, portanto, absorção de poupança no final da década passada, por conta dos desequilíbrios dos Estados Unidos - se observa entre os desenvolvidos.

Contrastando o período atual de globalização com o seu antecessor do final do século XIX, a conclusão é ainda mais surpreendente: os fluxos de capital, enquanto parcela da poupança e do investimento domésticos dos países pobres, mostram grau muito menor de importação de capital do que durante o padrão-ouro, apesar de os incentivos - dotações e preços relativos dos fatores - serem hoje bem maiores.

Ou seja, os dados definitivamente não corroboram a figura prevista na teoria - financiamento dos déficits em conta corrente dos países com escassez de capital por volumosos fluxos de capital oriundos dos países ricos, em busca tanto dos mais elevados rendimentos, quanto da diversificação dos seus riscos. O confronto da realidade com dois dos mais importantes pilares do raciocínio resumido nas páginas anteriores é, portanto, explícito. ${ }^{7}$

A constatação não é propriamente nova, tendo sido apresentada por um dos grandes expoentes contemporâneos do pensamento neoclássico (LUCAS, 1990) como um dos maiores contrastes entre a realidade e as teorias dominantes sobre as trocas internacionais: "por que o capital não flui dos países ricos para os pobres?" O "paradoxo de Lucas" é, assim, um primeiro desafio ao raciocínio convencional, que, no

7 "Thus, globalized capital markets are back, but with a difference. Capital transactions today seem to be mostly a rich-rich affair, consistent with the picture of modern capital flows as mostly 'diversification finance' rather than 'development finance'." Obstfeld e Taylor (2004, p. 249). 
entanto, raramente é mencionado quando se faz uso dos argumentos da diversificação internacional de carteiras e da atração de poupança externa. ${ }^{8}$

Vale ainda notar que um fenômeno próximo, que também intriga a literatura convencional e suscita vários debates, é o fato de aplicações financeiras, principalmente nos mercados de ações, terem um viés doméstico (home bias) - o que igualmente contradiz a teoria que sustenta a abertura. ${ }^{9}$ Porém, o maior dos desafios empíricos certamente não se refere a estes enigmas.

\subsection{Dados Relutantes: A Difícil Comprovação dos Benefícios da Abertura}

O fato de o capital fluir para os países em desenvolvimento em um montante muito menor do que o previsto pode não ser argumento suficiente para descartar a abertura ao mesmo; nada foi dito ainda a respeito dos seus benefícios. É sobre estes que se dá o segundo e mais importante esforço quantitativo: a mensuração dos efeitos da abertura financeira, na busca de comprovação das promessas teóricas, principalmente em relação ao crescimento. Os resultados ficam, para dizer o mínimo, muito aquém da robustez que autorizaria recomendações tão enfáticas como as dirigidas ao mundo em desenvolvimento ao longo das décadas de 1980 e 1990. Alguns autores envolvidos nesta cruzada chegam a manifestar explicitamente seu incômodo com os dados. ${ }^{10}$

As primeiras e mais destacadas tentativas de se medir tais relações são as de Quinn (1997) e de Rodrik (1998), com resultados contraditórios: o primeiro obtém correlação positiva entre mudanças na direção da abertura e taxas de crescimento, e o segundo não encontra nenhuma associação entre as proxies dos dois fenômenos. Essa discordância é um ponto de partida que suscita o desenvolvimento da pesquisa empírica em várias direções, a começar pelas formas de se medir a abertura financeira.

Enquanto Rodrik (1998) utiliza uma medida quase rudimentar (uma variável binária baseada nas compilações do Annual Report on Exchange Arrangements and Exchange Restrictions, AREAR, do FMI sobre a presença ou não de controles de capital), o estudo de Quinn (1997) atribui pesos distintos para o caráter parcial ou total dos controles, os tipos de fluxos, etc. A partir daí, o refinamento das proxies progrediu bastante, seja trabalhando com os próprios dados do $A R E A R$ (que a partir

8 As tentativas de explicação para esse contraste, no próprio livro de Obstfeld e Taylor (2004, cap. 8), giram em torno das deficiências institucionais dos países potencialmente recebedores dos fluxos, particularmente a falta de garantias do respeito ao direito de propriedade.

9 Ver, por exemplo, Lewis (1999).

10 Most of our research (...) has tried to draw inferences form a somewhat reluctant data". Bekaert e Harvey (2003, p. 45). 
de 1997 traz informações mais detalhadas), seja combinando-os com análises da legislação de cada país. ${ }^{11}$

Outra forma de quantificar a abertura também utilizada são as chamadas medidas quantitativas ou de facto (em oposição às qualitativas ou de jure, baseadas nas legislações ou registros oficiais). Estas, por sua vez, também se dividem segundo a variável econômica observada: grau de integração financeira (estoques de ativos e passivos externos geralmente em relação ao PIB); diferenciais de preços dos ativos (na suposição de que a integração os reduziria); paridades das taxas de juros (também na suposição de convergência com a liberdade de movimento dos capitais), e as correlações entre poupança e investimento domésticos, já comentadas. Como outra característica desta literatura, pode-se citar a predominância de análises crosscountry em relação a estudos de caso ou comparativos. Para tudo isso, a crescente disponibilidade de dados padronizados também é uma novidade relevante. ${ }^{12}$

Para além das questões metodológicas, o traço mais importante é mesmo a dificuldade de comprovação dos benefícios, apesar de todas as tentativas nas mais distintas direções. Economistas bastante destacados pela posição que ocupam no FMI, como Prasad et al. (2003), após uma primeira organização da discussão empírica, não conseguiam ir além da expressão de dúvidas diante do contraste das previsões teóricas com a realidade. Em outra linha, Gourinchas e Jeanne (2003) reputam como insignificantes ou "ilusórios" os ganhos identificáveis de bem-estar advindos da integração - facilmente superados por providências internas relativas à alocação eficiente de recursos e elevação da produtividade. Indo além, advogam que, se existirem, os benefícios devem se transmitir através de canais distintos daqueles presentes nos modelos neoclássicos tradicionais, afetando de maneira positiva a produtividade das nações receptoras.

Em outro exemplo, o trabalho de Edison et al. (2002) se vale de amplo leque de opções metodológicas, utilizando todos os indicadores (de jure e de facto) já tentados e incorporando novos dados de estoques de ativos e passivos externos. Examinam a interação com outros fatores que a literatura reputa fundamentais nesta relação (controlam a influência de instituições e regimes de política macroeconômica) e, finalmente, utilizam novidades então recentes nas técnicas de painel para tratar problemas estatísticos comuns em tais testes. As conclusões são explicitamente decepcionantes, além de tocarem em vários outros pontos relevantes.

11 Ver também Chinn e Ito (2006); Mody e Murshid (2005); Edwards (2005); Miniane (2004). Dos trabalhos brasileiros sobre o tema, provavelmente o mais completo é o de Damasceno (2008).

12 Kose et al. (2006) e Eichengreen (2001) trazem várias referências do debate e dos procedimentos metodológicos. 
Um deles é a associação da abertura com o que definem como "sucesso econômico", feita preservando uma consideração óbvia: correlação não é causalidade, e a evidência histórica esclarece que os successful countries só adotaram a abertura financeira depois de atingido um alto grau de desenvolvimento. ${ }^{13}$ Mais do que isso, são comentados alguns fatores estruturais, particularmente financeiros e institucionais, que poderiam estar impedindo tal relação esperada de se manifestar. Neste trabalho, mesmo eliminado este obstáculo, o resultado não é o pretendido.

Porém, outro ramo da literatura encara esses fatores de maneira distinta: procura medir os impactos indiretos da abertura sobre o crescimento por meio de dois canais: o investimento e o grau de desenvolvimento financeiro (estes sim, com papel relevante em regressões de crescimento). O fato é que também não se consegue demonstrar tal relação de maneira conclusiva. O próprio Rodrik (1998) não havia encontrado associação com o investimento, resultado também obtido por Kraay (1998), que usa diferentes alternativas para a variável independente. Quanto aos impactos sobre o aprofundamento financeiro, a correlação positiva presente em Klein e Olivei (1999) desaparece quando são excluídos da amostra os países da OCDE - o que o trabalho de Kraay (1998) igualmente sugere.

A resenha de Eichengreen (2001), diante de todas estas dificuldades, desafia a literatura a se reinventar, questionando explicitamente o caminho seguido até então. ${ }^{14}$ Porém, a revisão que propõe não parece tocar nas bases da sabedoria convencional. Suas sugestões são: um esforço para sofisticar as medidas e os métodos de análise, particularmente para dar conta dos distintos tipos de controles e de fluxos de capital, das diferenças entre os mercados abertos, da sequência seguida na abertura, além de melhorias nas bases de dados, e um aprimoramento na quantificação dos impactos microeconômicos da abertura, supostamente mais favoráveis e mais fáceis de captar. Foram estes, de maneira geral, os caminhos tentados pela literatura empírica convencional.

De um lado, proliferam os estudos sobre os efeitos da abertura no nível das empresas. Em um survey sobre o assunto, Forbes (2007) parte da suposição de que os fracos resultados empíricos da análise macro se devem exclusivamente às difi-

13 Fischer (1998, p. 2) lança mão de um argumento cuja lógica (ou falta dela) até surpreende: "There are two chief arguments in favor of capital-account liberalization. The first is that it is an inevitable step on the path of development, which cannot be avoided and should be embraced. After all, the most advanced economies all have open capital accounts".

14 "...if these caveats complicate the journey, the destination, from all appearances, remains the same. Officials and their advisers may differ on precisely when and how to liberalize international financial transactions so as to best ensure that capital inflows are channeled in productive directions (...) but there is little support for refusing to liberalize or (...) for reversing previous liberalization measures. (...) Given the breadth of support commanded by this synthesis, the lack of empirical substantiation of its fundamental tenets is worrisome indeed. If the evidence is really not there, it is high time to rethink the conventional wisdom."(p. 359-360) 
culdades de mensuração e acredita ser essa uma trilha promissora, tal qual teria acontecido com a literatura sobre a integração comercial. De acordo com a organização da autora, as evidências disponíveis nos estudos poderiam ser organizadas em cinco áreas, todas enfatizando os custos microeconômicos dos controles de capital. Estes tenderiam a: (i) reduzir a oferta de capital e ampliar as restrições financeiras, especialmente para firmas menores e/ou sem acesso ao mercado internacional de capitais; (ii) reduzir a disciplina de mercado, levando a uma alocação menos eficiente dos recursos; (iii) distorcer as decisões de firmas e indivíduos na tentativa de contorná-los ou reduzir seus custos; (iv) ter efeitos muito distintos em firmas e países diferentes dependendo das distorções já existentes, e (iv) serem burlados pelo alto custo e dificuldade para implementá-los. Como se vê, muda-se o nível de análise, mas vários dos pressupostos tradicionais permanecem.

Na outra direção, trabalhos que lidam com dimensões parciais da abertura também chegam a melhores resultados. Tratando especificamente dos mercados de ações, Bekaert e Harvey $(2003)^{15}$ relatam efeitos positivos sobre o crescimento após a integração ao mercado internacional - para a qual constroem uma série de proxies alternativas. De maneira geral, as previsões teóricas relativas a esse aspecto específico, comentadas na seção I, são corroboradas pelas evidências cross-country, com exceção da redução esperada na volatilidade das cotações.

Além destas duas tábuas de salvação, os autores costumam recorrer a um último argumento empírico: a falta de comprovação da associação entre abolição dos controles de capital e aumento da volatilidade cambial, vulnerabilidade a crises e outros efeitos adversos consolidados no senso comum: a mesma dificuldade para provar os benefícios se verificaria em relação aos malefícios. Mais do que isso, consideram a sucessão de crises recentes como mera evidência anedótica em cima da qual não se deveriam tirar conclusões gerais. ${ }^{16}$

Estas crises e o debate específico sobre elas não são tratados em detalhe aqui, mas sabe-se que fazem parte do mesmo caldo de cultura das evidências empíricas inconclusivas, e que fomentam dúvidas e dissidências importantes, novas fronteiras de pesquisa, e novas formulações para velhos argumentos. Estas são as outras direções de avanço no interior da visão convencional.

15 Entre vários outros trabalhos, especialmente Bekaert, Harvey e Lundblad (200la e 2001b).

16 Bekaert e Harvey (2003, p. 29-30) afirmam: "While this interpretation of how foreign capital can wreak havoc in the real economy of developing countries is widely accepted, it is surprising that empirical evidence for this view is very scarce (...). The assertion that globalization has gone too far for emerging economies is not supported by (...) empirical analysis”. Kose et al. (2006, p. 21) repetem: "...there is little formal empirical evidence to support the oft-cited claims that financial globalization in and of itself is responsible for the spate of financial crises that the world has seen over the last three decades". 


\subsection{Teria a Globalização Ido Longe Demais? Dissidências e Dúvidas na Visão Conven- cional}

A perda de apoio à abertura financeira, na sequência das crises, envolve episódios até pitorescos. Marcada com antecedência, a reunião da primavera do FMI e do Banco Mundial, em Hong Kong, em setembro de 1997, tinha como uma das discussões programadas a extensão das atribuições do Fundo, para incluir explicitamente nos seus articles of agreement a missão de promover a conversibilidade da conta financeira entre seus sócios. ${ }^{17}$ Região, data e tema dificilmente seriam menos apropriados. $\mathrm{O}$ assunto saiu de pauta sem conclusões definitivas, em meio à elevação do tom e ampliação do espectro das críticas não apenas a esse ponto, mas também à institucionalidade portadora daquelas ideias.

Profundos questionamentos à forma de atuação, às concepções e aos papéis do Fundo Monetário e propostas variadas de uma nova arquitetura financeira internacional (nem todas, é verdade, em uma direção progressista) são exemplos de uma agenda típica de crises, que acabou tendo pouquíssimos desdobramentos práticos. Mais importante é a participação, neste fogo cruzado contra um certo establishment, de autores com grande importância e respeito dentro da visão convencional, com posicionamento contrário à abertura financeira. Três são os personagens principais.

Em primeiro lugar, um eminente economista liberal, com largo currículo de defesa da abertura comercial, alerta para os perigos de um "mito capital": o de que o livre fluxo de capitais poderia ser defendido nos mesmos moldes em que se apregoa o livre comércio. Jagdish Bhagwati desenvolve, em pequeno e famoso artigo, uma argumentação bastante simples (BHAGWATI, 1998). Fazendo referência à instabilidade característica dos fluxos internacionais de capital (particularmente os de carteira), o eixo do raciocínio já está sugerido pela seção anterior: os benefícios da abertura financeira são apresentados por seus defensores apenas teoricamente (sem um esforço de quantificação adequado), enquanto os custos, bastante visíveis na forma das crises, não são considerados explicitamente. ${ }^{18}$

Criticando outro mito - o de que as crises da abertura poderiam ser eliminadas com o fortalecimento nos sistemas bancários ou mudanças no FMI - ele explica a disseminação da receita por uma mistura de ideologia e interesses dos agentes do mercado financeiro, costurados pelo "complexo Wall-Street - Tesouro" (que conteria também o departamento de Estado, o FMI, o Banco Mundial, etc).

17 Ver o n. 207 de Essays in International Finance (do qual os textos citados de FISCHER, 1998 e RODRIK, 1998 foram extraídos).

18 Uma tentativa de atualização desse raciocínio de J. Bhagwati, em sua homenagem e incorporando alguns dos desenvolvimentos teóricos tratados nas próximas seções, é feita em Snowden (2006). 
O segundo personagem dissidente - Joseph Stiglitz - tem, pela própria posição política e acadêmica que ocupou, suas posturas ecoadas ainda mais. Pronunciando-se, por um lado, enquanto economista-chefe do Banco Mundial, desfere pesadas críticas ao FMI, principalmente em relação à atuação na crise asiática e nos episódios semelhantes em outras economias emergentes. ${ }^{19}$ Por outro, o teórico, posteriormente agraciado com o Prêmio Nobel, defende uma típica second best solution: diante da violência das crises - que afetavam mesmo economias com fundamentos e políticas julgadas corretas - e da fraqueza teórica e empírica dos argumentos favoráveis à abertura, o melhor caminho seria controlar os fluxos de capital de curto prazo (principalmente, STIGLITZ, 2000).

Sua análise passa pelas falácias dos argumentos favoráveis - as diferenças, particularmente no aspecto da disponibilidade de informação, entre os mercados financeiros e de bens; a instabilidade e a "pró-ciclicalidade" dos fluxos de capital; a não verificação da ampliação dos recursos disponíveis para inversão e o fato de o investimento direto já ser suficiente para a disciplina macroeconômica - e pelas evidências empíricas (que também não condenariam o uso adequado de instrumentos de controle). A discussão relevante naquele momento seria justamente essa: quais as melhores formas de intervenção (e não mais acerca da sua necessidade).

O terceiro dos personagens é provavelmente o que mais mereça o rótulo de dissidente. Dani Rodrik foi, como apontado na seção anterior, o primeiro autor a contestar empiricamente os benefícios teóricos da abertura financeira (RODRIK, 1998), resultado ao qual agregava as diferenças entre a conversibilidade da conta corrente e da conta financeira do balanço de pagamentos (assimetria de informações, mercados contingentes incompletos, racionalidade limitada ou irracionalidade) e suas consequências (endividamento excessivo com descasamento de prazos e moedas; comportamento de manada, contágio e volatilidade; bolhas e efeitos danosos sobre as taxas de câmbio). Argumentando que nenhum dos graves problemas financeiros dos países em desenvolvimento seria aliviado com a medida em discussão (a ampliação das atribuições do FMI para exigir também a conversibilidade financeira), seu raciocínio e sua linguagem se afastam em muito das posturas convencionais.

O posicionamento deste autor, indo além, não se limita a essa visão quase consensual naquele momento sobre a conveniência de controles de entrada sobre o capital de curto prazo: são dele também uma das poucas contestações empíricas da associação entre abertura comercial e crescimento (RODRIGUEZ; RODRIK, 1999); um esforço de crítica à globalização em seus efeitos sobre a coesão social (RODRIK, 1997)

19 Seu artigo "O que eu aprendi com a crise mundial" (publicado originalmente pela revista New Republic e traduzido em português pela Folha de São Paulo de 15/04/2000) é o melhor exemplo. Seu livro Globalization and its discontents, traduzido para quase 40 idiomas diferentes (no Brasil: STIGLITZ, 2002), detalha essas e outras críticas ao processo de globalização. 
e, especificamente em relação aos controles, uma avaliação positiva sobre o "pacote heterodoxo" promovido pela Malásia em 1997 (KAPLAN; RODRIK, 2001).

Tratava-se, em suma, de um momento delicado para a visão dominante. As dissidências que surgem vão trazendo à tona vários dos aspectos explicitados pela literatura empírica e acrescentam elementos críticos que destoam do discurso convencional. O recuo na defesa da abertura (ou o posicionamento frontalmente contrário a ela em alguns casos) é uma demonstração clara destas dificuldades, mas não foi a única atitude verificada, como veremos a seguir.

\subsection{Admirável Mundo Novo: A Redescoberta da Periferia e suas Especificidades}

A quarta direção de avanço da visão convencional também parte da difícil realidade que a globalização financeira representou para os países em desenvolvimento. Porém, ao contrário dos autores dissidentes, envereda por outras fronteiras de pesquisa sem abandonar o tom geral favorável à abertura - e surgem conclusões de fato novas para a perspectiva dominante. Não são poucos nem irrelevantes os passos dados ao longo deste caminho, nem o seu aparente desfecho.

Pode-se localizar o ponto de partida em trabalhos que, na virada do século XX para o XXI, introduziam duas temáticas estranhas às abordagens tradicionais até então: a existência de um "medo de flutuar" (fear of floating) entre os países emergentes, e a ocorrência de "paradas súbitas" (sudden stops) nos fluxos de capitais para essas economias. Iniciemos com a primeira.

Com o mundo em meio a sucessivas crises que, invariavelmente, significaram o abandono de estratégias de câmbio fixo ou controlado, o tema dos regimes cambiais estava, naquele momento, na ordem do dia. A resenha de Edwards e Savastano (1999), por exemplo, descrevia um estado das artes em que, apesar do reconhecimento das vantagens da flexibilidade, notava-se a ausência de análises sobre o seu real funcionamento nos emergentes. Nesta trilha é que o debate iria avançar.

O artigo de Haussmann, Panizza e Stein (2001) foi um dos primeiros a mostrar que "diferentes países flutuavam de diferentes modos". Usando três indicadores de flexibilidade (o tamanho relativo do estoque de reservas internacionais e a volatilidade do câmbio comparada com a volatilidade deste próprio estoque e das taxas internas de juros), concluíam que o câmbio variava muito menos do que nos países desenvolvidos. As explicações para essa peculiaridade seriam o grau mais elevado de pass through e, principalmente, a alta parcela do passivo denominada em moeda estrangeira. Outros autores também apontavam que a flutuação do câmbio não era uma panaceia e que, na prática, imperava um "medo de flutuar" - justificado 
pelo fato de as grandes desvalorizações, ao invés de expansionistas como esperado, terem potencial contracionista (dada a dolarização dos passivos e a perda repentina de acesso aos mercados internacionais), inflacionário, ameaçarem a credibilidade da política econômica e prejudicarem o comércio exterior (CALVO; REINHART, 2000a e b).

Em suma, a partir de observações empíricas traduzidas em boa figura de linguagem, se avançava na descoberta de algumas diferenças importantes em relação aos países centrais. De particular interesse e poder explicativo, eram os chamados balance sheet effects: a denominação em moeda estrangeira de grande parte dos passivos (liability dollarization) fazia com que o valor da taxa de câmbio interferisse diretamente nas condições de solvência externa do país. O estoque de dívida importava e, por isso, o uso dos instrumentos de intervenção (reservas internacionais e taxas de juros) se mostrava menos custoso do que a permissão de um movimento errático daquele preço-chave. A visão do ajuste automático do balanço de pagamentos pelo câmbio flutuante, centrada apenas nos fluxos, ia sendo aprimorada.

Entretanto, a dinâmica destes fluxos também já recebia atenção especial. A explicar uma das causas das flutuações cambiais temidas e evitadas, a constatação de que as economias emergentes eram vítimas de "paradas súbitas" nas correntes financeiras internacionais (CALVO; REINHART, 2000c). As conclusões do principal trabalho sobre os sudden stops e seus efeitos (CALVO, 1998) apontavam os perigos da recorrência em déficits em conta corrente (principalmente, mas não só, quando financiados por fluxos de curto prazo e quando os recursos absorvidos eram direcionados ao setor non-tradable da economia): de repente o financiamento externo poderia "secar", levando a falências e destruição de capital humano e de canais financeiros domésticos.

Indo além, Kaminsky, Reinhart e Vegh (2004) documentam o que chamam de "pró-ciclicalidade" da absorção de capital: o endividamento se eleva nos períodos favoráveis e se contrai quando mais se precisa dele. Para os emergentes em particular, esse movimento cíclico seria acompanhado de perto pelas políticas fiscal e monetária, que, portanto, atuariam também na direção contrária à recomendável por uma estratégia cautelosa. Em outra boa figura de linguagem, nova descoberta é então revelada: when it rains, it pours!

A verificação e formalização desses eventos adversos, mesmo que suas causas não sejam suficientemente trabalhadas e que as sugestões de política decorrentes (centradas no fortalecimento do sistema financeiro doméstico) sejam bastante convencionais, parecem ser um importante avanço. Inclusive porque, em alguns casos, levam à recomendação de cautela para os países que ainda não haviam avançado na 
abertura financeira e a críticas às políticas contracionistas geralmente recomendadas em tais situações (CALVO, 1998). Por outro lado, é importante notar que todos esses achados (o "medo de flutuar", a "dolarização de passivos", as "paradas súbitas", os fluxos de capital "pró-cíclicos") serviam inicialmente como argumento para a defesa da dolarização dos países que apresentavam tais anomalias. ${ }^{20}$

A partir daí, os condicionantes à escolha de regimes cambiais e as interrupções no financiamento externo, além da consideração dos estoques de passivos e seus desdobramentos, passam a fazer parte de vários estudos, que buscam as razões destas especificidades.

De um lado, avançam os paralelos históricos com o período do padrão-ouro. Para Bordo e Flandreau (2001), ${ }^{21}$ tanto naquela época quanto atualmente, as possibilidades de escolha das combinações entre regime cambial e graus de abertura financeira, em países periféricos, acabam determinadas por um fator interno crucial: o grau de maturidade financeira, que impõe constrangimentos à política econômica. Seria esse o verdadeiro critério para distinguir "centro" (para quem a integração financeira ocorre independente do regime cambial) e "periferia" (na qual a integração obriga a adoção de regras rígidas para a taxa de câmbio, já que inexistem os golden points característicos do padrão-ouro). Atualmente é só com maturidade financeira que se pode flutuar; na ausência dela, é necessária uma âncora nominal, vinculada à moeda estrangeira, que sinalize políticas monetária e fiscal estáveis. O que também quer dizer que, no centro, a âncora é doméstica, dada pela credibilidade da política econômica, sempre questionada na periferia.

De outro lado, a discussão anterior levanta as questões que guiam o debate, no interior do mainstream, entre três explicações concorrentes: a "intolerância ao endividamento" (debt intolerance), o "descasamento de moedas" (currency mismatch) e o "pecado original" (original sin). As três, de certa maneira, buscam responder à mesma pergunta de fundo, a respeito das causas dos elementos peculiares redescobertos e que significam uma vulnerabilidade maior às crises financeiras. Na explicitação das diferenças entre elas, encontra-se uma rica demonstração dos avanços e limites da visão convencional a respeito da temática mais ampla aqui tratada.

Reinhart, Rogoff e Savastano (2003) iniciam seu artigo a respeito da "intolerância ao endividamento" respondendo de maneira direta à pergunta de fundo: a história importa! A constatação é a de que alguns países teriam capacidade muito mais baixa de tomar dívida no exterior, entrando em crise cambial, despertada pela

20 O texto de Calvo e Reinhart (2001) não deixa dúvidas. Haussmann (1999) segue raciocínio semelhante.

21 A seção 3 deste artigo tem o sugestivo título de "Brave new world: is financial vulnerability a discovery of the 1990s?". 
desconfiança dos credores, em patamares inferiores de endividamento (medidos a partir de indicadores como dívida externa/PIB ou dívida externa/exportações). Porém, a fragilidade seria recorrentemente ignorada, sucedendo-se os episódios de absorção e moratórias. Tal histórico de "caloteiros crônicos" (serial defaulters), junto com o registro de desequilíbrios decorrentes de políticas fiscal e monetária frágeis, explicariam os menores níveis de tolerância: todas as regressões realizadas corroboram a tese de que o passado condena. A causa do problema, portanto, recai sobre os fatores internos e, consequentemente, é das economias que sofrem desse mal que devem partir as medidas para, pelo menos, aliviar os sintomas (já que seria impossível apagar o passado adverso).

As recomendações são de políticas macroeconômicas corretas (com supervisão mais adequada do FMI), e de mecanismos para limitar a tomada de passivos, a fim de evitar os desastres comuns no final de ciclos de endividamento. Mesmo que os mecanismos para tal limitação não sejam explicitados, esta é uma conclusão não trivial para o arcabouço convencional: diante das fraquezas estruturais e históricas, e do risco que representa a absorção de recursos externos, seria preferível abrir mão das vantagens do acesso desimpedido ao mercado financeiro internacional.

Preservando a mesma hierarquia de culpados, a explicação do currency mismatch aponta para um aspecto distinto: o problema não seria propriamente o tamanho dos passivos externos, mas sim a moeda em que são denominados, em contraste com a sua estrutura de ativos. Goldstein e Turner (2004) partem explicitamente dos balance-sheet effects e definem uma estrutura descasada (de estoques, mas também de fluxos) como aquela em que os valores são sensíveis às variações na taxa de câmbio. Nestes casos, os episódios de crise cambial teriam efeitos devastadores ao destruir o valor líquido das empresas e da riqueza das famílias; as opções de enfrentamento da crise se tornariam mais custosas (a política monetária fica sobrecarregada diante da necessidade de controlar a desvalorização cambial e não penalizar excessivamente os agentes internos em dificuldade), e, diante de tudo isso, os países são obrigados a abrir mão das vantagens do câmbio flutuante, no fenômeno já descrito de fear of floating.

$\mathrm{Na}$ discussão das causas, a semelhança com a explicação do debt intolerance: origens internas, no passado e no presente de fraqueza institucional e de políticas macroeconômicas fracas. Especificamente, são enumerados como culpados a falta de incentivos e instrumentos para hedge cambial; o passado inflacionário; as falhas de informação que diminuem a eficiência da disciplina de mercado; os problemas de regulação no sistema financeiro doméstico; as políticas de endividamento ruins, e, não menos importante, a falta de um mercado local de títulos que evitasse o acesso obrigatório ao endividamento em moeda estrangeira. Coerentemente, as 
sugestões de enfrentamento incluem algumas medidas no plano internacional, mas se concentram nas providências internas: adoção do câmbio flutuante (a incerteza sobre o valor da moeda estrangeira desincentiva o descasamento) acompanhado do regime de metas de inflação; acúmulo de reservas internacionais para fazer frente às obrigações externas, junto com a redução da indexação da dívida interna à taxa de câmbio, e prioridade total ao desenvolvimento do mercado local de títulos, permitindo hedge cambial em larga escala e facilitando o acesso de bancos estrangeiros ao sistema financeiro local.

É em relação a essa atribuição de responsabilidades que a terceira explicação mais avança e se distancia das outras duas (e da tradição da análise convencional). Em vários trabalhos, organizados no livro de Eichengreen e Haussmann (2005), é desenvolvida a ideia de que o problema das economias emergentes seria um defeito inato, um "pecado original", cujas causas estariam além do seu controle. Eichengreen, Haussmann e Panizza (2005a) identificam o ponto: a incapacidade de emitir dívida externa denominada em moeda local. No mesmo texto, os autores documentam a "dor do pecado original", com os elementos já presentes nas explicações anteriores: o descasamento de moedas (uma manifestação, um sintoma, do problema de fundo) e seus efeitos; a dificuldade de dar flexibilidade à taxa de câmbio e aproveitar seus benefícios; a sobrecarga da política monetária levando à oscilação das taxas de juros; os fluxos de capital mais voláteis e reversíveis, e o baixo rating de crédito.

Em Eichengreen, Haussmann e Panizza (2005b), o objetivo é desvendar tal mistério, e os resultados se mostram surpreendentes. Entre todos os "suspeitos usuais" testados (nível de desenvolvimento; credibilidade da política monetária e taxa de inflação; fundamentos da política fiscal e condições de solvência interna; qualidade das instituições; grau de abertura comercial; desenvolvimento do mercado local de títulos), apenas o tamanho da economia parece de alguma maneira "confessar o crime". Daí, os autores tiram a quase herética sugestão de que a causa poderia ser "algo na estrutura do sistema financeiro internacional", ${ }^{22}$ mais do que a qualidade das políticas e instituições locais. Assim, todas as providências para enfrentar as falhas internas são medidas necessárias, mas não suficientes. Acima de tudo, são fatores externos que não permitem a denominação das dívidas em mais do que "um punhado" de moedas.

A explicação para esse mistério passaria pela existência de custos de transação (fazendo com que os benefícios da diversificação de portfólio em diferentes moedas sejam decrescentes); pelas "desvantagens do atraso" (path dependence), e pelas externalidades de rede (já estão criadas redes de comércio e finanças nas poucas

22 Eichengreen e Haussmann (2005a, p. 6); na mesma página os autores falam em “...inherited burden, almost irrespective of the policies of their governments." 
moedas livres do pecado. Portanto, na formulação de propostas para a "redenção" (EICHENGREEN; HAUSSMANN, 2005b), não bastariam apenas iniciativas domésticas, sendo necessário um esforço multilateral, que envolvesse as instituições financeiras internacionais e os países desenvolvidos, na criação de um mercado internacional de dívida nas moedas emergentes.

Essa é, de fato, a grande diferença entre as três visões, explícita nas ácidas críticas às concepções do original sin por parte dos defensores das outras duas visões. ${ }^{23}$ Se, neste aspecto, não há dúvidas quanto à distância em relação à visão tradicional, o mesmo não pode ser dito das saídas propostas. Ao apostar exclusivamente em medidas no plano internacional, estratégias de autodefesa - desde a acumulação de reservas (que parece um consenso prático atualmente), até limitações à absorção de capital estrangeiro, sugeridas pelos diagnósticos concorrentes - são explícita e surpreendentemente rejeitadas em nome dos tradicionais benefícios da abertura, sem levar em conta os inúmeros problemas a eles relacionados. ${ }^{24}$

Assim, a redescoberta da periferia pelo mainstream chega a um desfecho paradoxal. A visão que em alguns aspectos mais avança - por inverter a determinação causal dos principais problemas financeiros dos países em desenvolvimento - acaba retornando às concepções originais sobre os benefícios da integração, cuja pouca aderência à realidade já havia suscitado mudanças teóricas e questionamentos importantes mesmo entre os economistas mais tradicionais. A própria visão do debt intolerance, muito mais conservadora ao atribuir os problemas a fatores internos e apresentar como saída o bom comportamento, acaba se revelando mais adaptada à realidade financeira recém-descoberta, marcada por paradas súbitas, fluxos de capital pró-cíclicos e medo de flutuar.

23 "... unless these weaknesses are addressed, the notion that the 'original sin' of serial defaulters can be extinguished through some stroke of financial engineering, allowing these countries to borrow in the same amounts (...) as more advanced economies, much less at the same interest rates, is sheer folly."(REINHART; ROGOFF; SAVASTANO, 2003, p. 4). "We see the origins of currency mismatch in past and present weaknesses in economic policies and institutions in emerging market themselves rather than in imperfections in international markets" (GOLDSTEIN; TURNER, 2004, p. 2). Em Eichengreen, Haussmann e Panizza (2003), os próprios autores se propõem a analisar as diferenças entre as três visões e suas consequências práticas e teóricas. No livro de Goldstein e Turner (2004), principalmente na introdução e no capítulo 3, suas críticas ao pecado original são detalhadas.

24 "If a country is unable to borrow abroad in its own currency (...) when it accumulates a net debt, as developing countries are expected to do, it will have an aggregate currency mismatch on its balance sheet. Of course, such a country can take various steps to eliminate that mismatch or prevent it (...). Most obviously, it can decide not to borrow. A financially autarchic country will have no currency mismatch because it has no external debt, even though it still suffers from original sin (...) But these response clearly has costs; the country (...) will forgo all the benefits, in the form of additional investment finance and consumption smoothing, offered by borrowing abroad. Alternatively, the government can accumulate foreign reserves to match its foreign obligations. In this case the country eliminates its currency mismatch by eliminating its net debt (...). But this too is costly: the yield on reserves is generally significantly below the opportunity cost of funds." (EICHENGREEN; HAUSSMANN; PANIZZA, 2005a, p. 13, grifos nossos). 
Não é o caso de subestimar toda a evolução teórica relatada, mas sim de reconhecer os seus limites e, principalmente, a ausência de uma explicação que articule de maneira satisfatória todos os novos elementos trazidos à tona ao longo do caminho. Como se verá a seguir, a quinta e última frente de mudanças passa ainda mais longe de uma revisão profunda.

\subsection{A Globalização Reexaminada: Benefícios Colaterais e Pré-Requisitos Mínimos}

Já foi comentada, na seção 3.2, a desesperança com que Prasad et al. (2003) encaravam as pesquisas sobre a temática aqui tratada. Alguns anos depois, os mesmos destacados economistas se valem dos progressos e caminhos tentados por essa literatura e, num nítido esforço de resgate da visão convencional, fazem uma reavaliação (reappraisal) dos impactos da globalização financeira sobre os países em desenvolvimento, apresentando um novo arcabouço analítico (KOSE et al., 2006). Este último grito, oriundo de representantes perfeitos do mainstream economics, pode ser tomado como um ponto de chegada do quadro evolutivo aqui pintado.

O texto de 2003 já apontava a existência de canais entre a abertura e o crescimento, mesmo que sem identificar resultados conclusivos. ${ }^{25} \mathrm{~A}$ mudança de paradigma agora proposta trata exatamente disso: substituir a busca dos resultados nesses canais de difícil verificação empírica, pela postulação da existência de mecanismos indiretos de transmissão entre um fenômeno e outro; os "benefícios colaterais" da abertura tomam a frente em relação aos já conhecidos benefícios tradicionais.

De maneira complementar aos canais diretos, os fluxos livres de capital seriam responsáveis por transformações em três direções que, afetando a produtividade total dos fatores (e não o investimento ou o produto em si), elevariam a taxa de crescimento. São eles: i) o desenvolvimento do mercado financeiro; ii) o desenvolvimento institucional, e iii) a disciplina sobre a política macroeconômica (já presente na lista inicial). A nova perspectiva explicaria as dificuldades para encontrar resultados positivos nas correlações, além de fornecer um alento aos desesperançosos e reeditar o pedido de paciência aos que contestam o caminho das reformas.

À parte o reconhecimento da fraqueza do argumento da poupança externa - e, notese, a evidência do rich-rich affair, tratado na seção 3.1, não é sequer citada -, esta nova perspectiva tem um problema sério. Também é destaque, na literatura empíri-

25 "Theoretical models have identified a number of channels through which international financial integration can promote economic growth in developing countries. However, a systematic examination of the evidence suggests that it is difficult to establish a strong causal relationship. In other words, if financial integration has a positive effect on growth, there is as yet no clear and robust empirical proof that the effect is quantitatively significant" (p. 5) 
ca, o fato de que os benefícios, mesmo que colaterais, tendem a se verificar apenas nos casos em que determinados patamares ou pré-requisitos mínimos (thresholds) já tenham sido atingidos; nos demais, a abertura resulta em ampliação de riscos. O ponto a destacar é que tais patamares se referem, justamente, aos mesmos fatores apontados como benefícios colaterais: haveria êxito só em países já com grau razoável de aprofundamento financeiro, com desenvolvimento institucional acima de certo nível, e com sólidas instituições e práticas de política econômica (além de elevada integração comercial). Este curto-circuito lógico, entre consequências e pré-requisitos, é inclusive reconhecido explicitamente pelos autores. ${ }^{26}$

No entanto, longe de questionar de maneira mais ampla a abordagem e a própria defesa da abertura, isto abre espaço para a reafirmação de antigas ideias, com novas embalagens. De um lado, o raciocínio dos pré-requisitos nada mais é do que recolocação, sem grandes novidades relevantes, da velha questão, não resolvida, da sequência da liberalização: estão mencionados o caráter prematuro da abertura a ser evitado, os riscos envolvidos, as chances de comprometer o rumo certo e as providências necessárias (mesmo que quase todas estejam vinculadas aos supostos benefícios). De outro lado, apresenta-se o que seria uma vantagem adicional desta perspectiva: a possibilidade e a necessidade de analisar caso a caso as reformas e os cuidados necessários para que a globalização resulte, no fim das contas, em mais benefícios do que riscos.

Entretanto, acima de tudo, trata-se de uma tentativa de resgatar a agenda da abertura, depois das sérias dificuldades empíricas e revisões pelas quais é obrigada a passar. Tentativa que, ao fim e ao cabo, se mostra pouco satisfatória, não apenas pelas inconsistências internas, mas também por praticamente ignorar grande parte dos avanços teóricos surgidos no interior da própria visão convencional, além de não dar resposta para alguns dos contrastes entre a realidade empírica e os pressupostos dos tradicionais argumentos favoráveis à abertura financeira.

26 "... there is plenty of evidence that premature opening of the capital account without having in place well-developed and well-supervised financial sectors, good institutions, and sound macroeconomic policies can hurt a country by making the structure of inflows unfavorable and by making the country vulnerable to sudden stops or reversals of flows. (...) ... it is the interaction between financial globalization and this set of initial conditions that determines growth and volatility outcomes. (...) Note that most (...) of the elements on the list of threshold conditions are identical to the list of collateral benefits. In other words, financial globalization serves as catalyst for a number of important collateral benefits but can greatly elevate the risks to benefits ratio if the initial conditions in these dimensions are inadequate." (p. 34-35) 


\section{Considerações Finais}

O objetivo deste artigo foi descrever como, ao longo dos últimos tempos e em resposta a uma série de dificuldades de diferentes naturezas, evoluiu a visão convencional sobre a abertura financeira. Como é inerente a qualquer trabalho desta natureza (mesmo que isso nem sempre seja explicitado), a leitura aqui feita partiu de uma concepção assumidamente crítica sobre esta frente de reforma tal como implementada nas últimas décadas nas economias em desenvolvimento. Assim construída, a resenha desta literatura foi capaz de revelar alguns traços importantes.

Tomando-se, de um lado, as formulações originais e, de outro, as evidências colhidas e as ideias desenvolvidas nas cinco frentes de reação, pode-se afirmar que, sem dúvida, as concepções evoluíram - e de maneira geral evoluíram positivamente segundo a perspectiva aqui privilegiada. O conteúdo e principalmente a articulação entre as diferentes frentes desta evolução, porém, se revelam insatisfatórios, basicamente por três grandes motivos: (i) a inadequação dos pressupostos macroeconômicos de inspiração clássica; (ii) a crença na eficiência alocativa e nos ajustamentos automáticos promovidos pelas forças de mercado, e (iii) o tratamento insuficiente das especificidades dos países em desenvolvimento.

Quanto ao primeiro ponto, parece claro que a concepção pré-keynesiana de precedência lógica da poupança em relação ao investimento é responsável por uma série de problemas, de que são exemplos a não verificação prática da contribuição da poupança externa aos países em desenvolvimento e a dificuldade em compreender as elevadas correlações entre níveis de investimento e poupança domésticos (interpretadas como evidência do baixo grau de integração).

Por outro lado, e já entrando na segunda razão para a insatisfação, a hipótese de mercados eficientes só é desafiada por algumas apreciações dissidentes sobre os fenômenos em tela. O problema é que nem este elemento isolado de crítica parece ser incorporado em sua plenitude, sendo ignorado pela ampla maioria dos demais analistas. Mesmo quando a realidade contesta um dos pilares da argumentação favorável à abertura - o mito da diversificação internacional de riscos, com os capitais livres esgotando as possibilidades de ganhos extraordinários através de uma carteira verdadeiramente global -, os dados servem não para reanalisar os determinantes da dinâmica destes fluxos, mas sim para culpar as fraquezas e insuficiências das economias em desenvolvimento alijadas.

Em terceiro lugar, no que se refere ao tratamento das especificidades de tais países, também se pode dizer que os inegáveis avanços permanecem isolados e não são levados às últimas consequências. Se a literatura tratada na seção 3.4 foi capaz de 
endogeneizar elementos como o "medo de flutuar" ou as "paradas súbitas", não parece, no entanto, ter respostas suficientes para a dinâmica internacional que leva a estes episódios; se alguns autores chegam a afirmar que a causa última do "pecado original" se localiza em elementos alheios ao controle dos que sofrem deste mal, acabam caindo no extremo oposto ao rejeitar qualquer iniciativa de auto-defesa, com base nos mesmos benefícios teóricos originais. Por fim, na tentativa mais recente de reconstruir o ideário favorável à abertura, a todas essas insuficiências vêm se somar problemas de lógica na argumentação.

Em suma, a visão convencional revela-se incapaz de responder, de forma abrangente e integrada, ao conjunto de desafios a ela impostos, em uma evolução que deixa para trás a perspectiva dos benefícios tradicionais, mas é marcada por avanços pontuais e limitados, quando não é acompanhada de recuos. Um referencial teórico distinto parece ser necessário para lidar com este tema fundamental.

\section{Referências}

ARROW. K. J. Essays in the theory of risk-bearing. Chicago: Markham, 1971.

BHAGWATI, J. The capital myth: the diference between trade in widgets and dollars. Foreign Affairs, v. 77, n. 3, p. 7-12, 1998.

BEKAERT, G.; HARVEY, C. R. Emerging markets finance. Journal of Empirical Finance, n. 10, p. 3-55, 2003.

BEKAERT, G.; HARVEY, C. R.; LUNDBLAD, C. Emerging equity markets and economic development. Journal of Development Economics, v. 66, n. 2, p. 465504, 2001a.

Does financial liberalization spur growth?. NBER working papers 8245. Cambridge: National Bureau of Economic Research, $2001 \mathrm{~b}$.

BORDO, M.; FLANDREAU, M. Core, periphery, exchange rate regimes, and globalization. NBER working papers 8584. Cambridge: National Bureau of Economic Research, 2001.

BRESSER-PEREIRA, L. C.; GALA, P. Por que a poupança externa não promove crescimento. Revista de Economia Política, v. 27, n. 1, p. 3-19, 2007.

CALVO, G. Capital flows and capital market crises: the simple economics of sudden stops. Journal of Applied Economics, v. 1, n. 1, p. 33-54, 1998.

CALVO, G.; IZQUIERDO, A.; MEJIA, L. F. On the empirics of sudden stops: the relevance of balance-sheet effects. NBER working papers 10520. Cambridge: National Bureau of Economic Research, 2004.

CALVO, G.; REINHART, C. Fear of floating. NBER working papers 7993. Cambridge: National Bureau of Economic Research, 2000a. 
. Fixing for your life. NBER working papers 8006. Cambridge: National Bureau of Economic Research, 2000b.

.When capital flows come to a sudden stop: consequences and policy. In: KENEN, P.; SWOBODA, A. (Ed.). Reforming the international monetary and financial system. Washington: International Monetary Fund, 2000c.

. Reflections on dollarization. In: ALESINA, A.; BARRO, R. (Ed.). Currency unions. Stanford: Hoover Institute Press, 2001.

CARVALHO, F. J. C.; SICSÚ, J. Controversias Recentes sobre os Controles de Capitais. Revista de Economia Política, v. 24, n. 2, p. 163-184, 2004.

CHINN, M.; ITO, H. What matters for financial development? Capital controls, institutions, and interactions. Journal of Development Economics, v. 81, n. 1, p. 163-192, 2006.

COLANDER, D.; HOLT, R.; ROSSER JR., J. B. The changing face of mainstream economics. Review of Political Economy, v. 16, n. 4, p. 485-499, 2004.

CUNHA, A. M. Crise no Pacífico asiático: causas e consequências. Tese (Doutorado) - IE-Unicamp, Campinas, 2001.

DAMASCENO, A. Integração financeira internacional e crescimento econômico: uma crítica à abordagem convencional. Economia e Sociedade, n. 16, p. 171198, 2007.

. Integração financeira internacional, fluxos internacionais de capitais e crescimento econômico: teoria e evidência. Tese (Doutorado) - IE-Unicamp, Campinas, 2008.

DEQUECH, D. Neoclassical, mainstream, orthodox, and heterodox economics. Journal of Post-Keynesian Economics, v. 30, n. 2, p. 279-302, 2007-2008.

EDISON, H. J.; LEVINE, R.; RICCI, L.; SLØK, T. International financial integration and economic growth. Journal of International Money and Finance v. 21, n. 6, p. 749-776, 2002.

EDWARDS. S. Capital controls, sudden stops, and current account reversals. NBER working papers 11170. Cambridge: National Bureau of Economic Research, 2005.

EICHENGREEN, B. Capital account liberalization: what do cross-country studies tell us? World Bank Economic Review, v. 15, n. 3, p. 341-365, 2001.

EICHENGREEN, B.; HAUSMANN, R. Introduction: debt denomination and financial instability in emerging market economies. In: . (Ed.). Other people's money: debt denomination and financial instability in emerging-market economies. Chicago: University of Chicago Press, 2005a.

. Original sin: the road to redemption. In: . (Ed.). Other people's money: debt denomination and financial instability in emerging-market economies. Chicago: University of Chicago Press, 2005b. 
EICHENGREEN, B.; HAUSMANN, R.; PANIZZA, U. Currency mismatches, debt intolerance and original sin: why they are not the same and why it matters NBER working papers 10036. Cambridge: National Bureau of Economic Research, 2003.

. The pain of original sin. In: EICHENGREEN, B.; HAUSMANN, R. (Ed.). Other people's money: debt denomination and financial instability in emergingmarket economies. Chicago: University of Chicago Press, 2005a.

. The mystery of original sin. In: EICHENGREEN, B.; HAUSMANN, R. (Ed.). Other people's money: debt denomination and financial instability in emergingmarket economies. Chicago: University of Chicago Press, 2005b.

FELDSTEIN, M.; HORIOKA, C. Domestic saving and international capital flows. Economic Journal, n. 90, p. 314-329, June 1980.

FISCHER, S. Capital-account liberalization and the role of IMF. Essays in International Finance 207. Princeton: Princeton University Press, p. 1-10, 1998.

FORBES, K. The microeconomic evidence on capital controls: no free lunch. In: EDWARDS, S. (Ed.). Capital controls and capital flows in emerging economies: policies, practices and consequences. Chicago: The University of Chicago Press, 2007.

GOLDSTEIN, M.; TURNER, P. Controlling currency mismatches in emerging markets. Washington DC: Institute for International Economics, 2004.

GOURINCHAS, P.; JEANNE, O. The elusive gains from international financial integration. NBER working papers 9684. Cambridge: National Bureau of Economic Research, 2003.

HAUSMAN, R. Should there be five currencies or one hundred and five? Foreign Policy, n. 116, p. 65-79, 1999.

HAUSMAN, R.; PANIZZA, H.; STEIN, E. Why do countries float the way they float?. Journal of Development Economics v. 66, n. 2, p. 387-414, 2001.

KAMINSKY, G.; REINHART, C.; VEGH, C. When it rains, it pours: procyclical capital flows and macroeconomic policies. NBER working papers 10780. Cambridge: National Bureau of Economic Research, 2004.

KAPLAN, E.; RODRIK, D. Did the malaysian capital controls work? NBER working papers 8142. Cambridge: National Bureau of Economic Research, 2001.

KLEIN, M.; OLIVEI, G. Capital account liberalization, financial depth, and economic growth. NBER working papers 7384. Cambridge: National Bureau of Economic Research, 1999.

KOSE, M. A.; PRASAD, E.; ROGOFF, K.; WEI, S. Financial globalization: a reappraisal. IMF Working Paper 06/089, 2006.

KRAAY, A. In search of the macroeconomic effect of capital account liberalization. Washington: World Bank, 1998.

LEWIS, K. K. Trying to explain home bias in equities and consumption. Journal of Economic Literature v. 37, n. 2, p. 571-608, 1999. 
LUCAS, R. E. Why doesn't capital flow from rich to poor countries? American Economic Review, n. 80, p. 92-96, May 1990.

MINIANE, J. A new set of measures on capital account restrictions. IMF Staff Papers, v. 50, n. 2, p. 276-308, 2004.

MODY, A.; MURSHID, A. P. Growing up with capital flows. Journal of International Economics v. 65, n. 1, p. 249-266, 2005.

OBSTFELD, M. Risk-taking, global diversification, and growth. American Economic Review, v. 84, n. 5, p. 1310-1329, 1994.

OBSTFELD, M.; ROGOFF, K. Foundations of International Macroeconomics. Massachusetts: MIT Press, 1996.

OBSTFELD, M.; TAYLOR, A. M. Global capital markets: integration, crisis, and growth. Cambridge: Cambridge Univesity Press, 2004.

PRASAD, E.; ROGOFF, K.; WEI, S.; KOSE, M. A. . Effects of financial globalization on developing countries: some empirical evidence. IMF Occasional Paper 220, 2003.

QUINN, D. The correlates of change in international financial regulation. American Political Science Review v. 91, n. 3, p. 531-551, 1997.

REINHART, C.; ROGOFF, K.; SAVASTANO, M. Debt intolerance. NBER Working Papers 9908. Cambridge: National Bureau of Economic Research, 2003.

RESENDE, M. F. C. Troca intertemporal entre economias desenvolvidas e em desenvolvimento. Revista de Economia Contemporânea v. 10, n. 1, p. 89-114, 2006.

RODRIGUEZ, F.; RODRIK, D. Trade policy and economic growth: a skeptic's guide to cross-national evidence. NBER Working Papers 7081. Cambridge: National Bureau of Economic Research, 1999.

RODRIK, D. Has globalization gone too far? Washington: Institute of International Economics, 1997.

Who needs capital-account convertibility? Essays in International Finance 207. Princeton: Princeton University Press, 1998. p. 55-65.

SICSÚ, J.; FERRARI FILHO, F. (Org.). Câmbio e controles de capitais: avaliando a eficiência de modelos macroeconômicos. Rio de Janeiro: Campus, 2006.

SNOWDEN, N. Myth, sin and redemption in capital account liberalization. The World Economy, v. 29, n. 11, p. 1581-1597, 2006.

STIGLITZ, J. Capital market liberalization, economic growth, and instability. World Development v. 28, n. 6, p. 1075-1086, 2000. . A globalização e seus malefícios. São Paulo: Futura, 2002. 